\title{
Precipitation and Latent Heating Characteristics of the Major Tropical Western Pacific Cloud Regimes
}

\author{
CHRISTIAN JAKOB \\ Monash University, Melbourne, Australia \\ COURTNEY SCHUMACHER \\ Texas A\&M University, College Station, Texas
}

(Manuscript received 27 June 2007, in final form 5 December 2007)

\begin{abstract}
An objective tropical cloud regime classification based on daytime averaged cloud-top pressure and optical thickness information from the International Satellite Cloud Climatology Project (ISCCP) is combined with precipitation and latent heating characteristics derived using the Tropical Rainfall Measuring Mission (TRMM) Precipitation Radar (PR). TRMM precipitation information is stratified into the ISCCP regimes in the tropical western Pacific (TWP), revealing the following three major precipitation regimes: a heavy $\left(12 \mathrm{~mm} \mathrm{day}^{-1}\right)$ precipitation regime dominated by stratiform precipitation and top-heavy latent heating; a regime with moderate $\left(5 \mathrm{~mm}\right.$ day $\left.^{-1}\right)$ precipitation amounts, mostly convective in nature with more midlevel latent heating; and a low $\left(2 \mathrm{~mm} \mathrm{day}^{-1}\right)$ precipitation regime with a relatively large rain contribution from shallow convection, compared to the other regimes. Although three of the ISCCP cloud regimes are linked to the more convective, moderate precipitation regime, only one of the cloud regimes is associated with the more stratiform, top-heavy latent heating regime, making the ISCCP regimes a potentially useful tool for the further study of this dynamically important tropical weather state. Similarly, only one cloud regime is associated with the more shallow convective precipitation regime.

In terms of the TWP, precipitation and latent heating are dominated by the relatively infrequent $(15 \%)$ occurrence of the strongly precipitating top-heavy latent heating state and by the frequent $(>30 \%)$ occurrence of one of the more moderately precipitating convective states. The low precipitation/shallow cumulus regime occurs often (i.e., $25 \%$ of the time) but does not contribute strongly to the overall precipitation and latent heating. Each of these regimes also shows distinct geographical patterns in the TWP, thus providing insight into the distribution of convective and stratiform rain across the tropics. This study confirms the potential usefulness of the objective regime classification based on ISCCP, and it opens several new avenues for studying the interaction of convection with the large-scale tropical circulation.
\end{abstract}

\section{Introduction}

The weather and climate of the tropics are driven by the interaction of large-scale circulation features and convection. The mean tropical climate and its seasonal variation are characterized by easily distinguishable migrating bands of high values of precipitation in the intertropical convergence zone (ITCZ). The largest interannual tropical variation, the El Niño-Southern Oscillation (ENSO) phenomenon, is associated with the

Corresponding author address: Christian Jakob, School of Mathematical Sciences, Monash University, Clayton VIC 3800, Australia.

E-mail: christian.jakob@sci.monash.edu.au movement of regions of active convection between the tropical western and central Pacific Ocean. On intraseasonal time scales, the Madden-Julian oscillation (MJO; Madden and Julian 1971, 1972) is characterized by eastward migrating regions of strong convection in the Indian and western Pacific Oceans. On shorter or weather time scales, convectively coupled waves and tropical cyclones are all easily identifiable by their convection and precipitation signatures. These examples highlight the intricate coupling of the tropical circulation with convection and its associated cloud and precipitation signatures.

The key to the interaction of convection with the large-scale circulation is the diabatic heating associated with condensation, evaporation, and radiative and 
transport processes in convectively driven cloud systems and its vertical and horizontal distribution throughout the tropics. It is well known that variations in the vertical structure of diabatic heating lead to variations in the dynamical "response" to this heating (e.g., Geisler 1981; Hartmann et al. 1984; DeMaria 1985; Sui and Lau 1989; Wu et al. 2000; Chiang et al. 2001; Lin et al. 2004). Given the importance of diabatic heating variations, it is not surprising that a large number of studies have attempted to elucidate those structures from observations such as in situ sounding arrays (e.g., Reed and Recker 1971; Yanai et al. 1973; Nitta and Esbensen 1974; Thompson et al. 1979; Johnson 1984; McBride et al. 1989; Frank et al. 1996) and, more recently, satellite observations (e.g., Schumacher et al. 2004; Shige et al. 2004; Tao et al. 2006). Although the vertical structure of diabatic heating is generally complex, the simplification into a convective and stratiform heating mode (e.g., Houze 1982, 1989; Mapes and Houze 1995; Houze 1997; Schumacher et al. 2004) has proven useful for the first-order conceptual description of convective systems and their interaction with the large-scale circulation.

A recent analysis of data from the International Satellite Cloud Climatology Project (ISCCP; Schiffer and Rossow 1983; Rossow and Schiffer 1999) has revealed that tropical weather and climate can be usefully summarized by a small set of recurring weather states as identified by their cloud signatures (Jakob and Tselioudis 2003; Rossow et al. 2005). Agreeing with this idea are Mapes et al. (2006), who have more recently put forth the idea that tropical convective systems on all scales are composed of a limited set of "stretched building blocks." Although the importance of such regime or building block separation for the understanding of tropical climate remains a matter of discussion, at a minimum it provides a possibility for studying its characteristics in a simplified framework. It furthermore moves the study of convection in the tropics from one dominated by geography (e.g., west Pacific versus east Pacific) to one dominated by phenomena (e.g., cloud distributions as defined by the ISCCP regimes). This in turn enables the use of a variety of data sources to thoroughly describe and understand the characteristics of the individual regimes, and to use that knowledge to study their respective influence on tropical climate. This has been explored by Jakob et al. (2005), who examined the radiative and thermodynamic characteristics of the ISCCP regimes in the tropical western Pacific (TWP) using the rich data sources of the Atmospheric Radiation Measurement Program (ARM; Stokes and Schwartz 1994; Ackerman and Stokes 2003) in the region. Because of measurement limitations, this study was unable to characterize one of the most important aspects of the ISCCP regimes-their precipitation and hence, their latent heating behavior. The first aim of the present study is to better describe these regime characteristics using additional data.

A recent data source for the study of tropical precipitation and tropical latent heating is the National Aeronautics and Space Administration (NASA) Tropical Rainfall Measuring Mission (TRMM) satellite (Simpson et al. 1988; Kummerow et al. 1998). Recently, Schumacher and Houze (2003a) and Schumacher et al. (2004) have used TRMM data to describe tropical precipitation and its related latent heating profile characteristics. They showed that the percent of total rain that is stratiform varies between $20 \%$ and $60 \%$ across the tropics. Using simple assumptions about the different latent heating structures in the convective and stratiform regions of convective systems, they used the rain fraction information to elucidate the geographic variations in the height of maximum heating associated with tropical convective systems. Because of the sampling characteristics of TRMM, the analysis from each of the studies above had to be limited to time scales of a season or longer.

Following the strategy used by Jakob et al. (2005) for ARM data, the regime separation proposed by Rossow et al. (2005) will be used to study the mean characteristics of precipitation identified in Schumacher and Houze (2003a) in the context of the ISCCP regimes. For example, we can explore the relationship between an individual ISCCP regime and its precipitation/latent heating characteristics in an attempt to understand the observed long-time mean geographic variations in stratiform precipitation fraction as a variation in the occurrence of the different ISCCP regimes. Furthermore, we can identify those cloud regimes that contribute the most to the precipitation and latent heating in a particular region. This in turn can provide a focus for further research and potential guidance for the development of climate and numerical weather prediction (NWP) models in which convection and the resulting cloud fields are unresolved and therefore need to be parameterized.

It is the second aim of this study to exploit the relationships between the ISCCP regimes and TRMMderived latent heating characteristics to better understand the observed distribution of convective and stratiform precipitation in the tropics.

To achieve the aims outlined above, this study combines the information from the currently separate ISCCP and TRMM analyses of Rossow et al. (2005) and Schumacher and Houze (2003a). Daily averaged data from both sources are used to establish the precipita- 
tion and latent heating characteristics of the ISCCPbased cloud regimes and then to describe observed mean precipitation patterns in terms of the ISCCP regimes. For both practical reasons and to highlight the methodological aspects of the study, we limit this first attempt at combining the two data sources to the TWP. A comparison of the Jakob et al. (2005) and Rossow et al. (2005) studies shows that the TWP contains all of the regimes observed in the entire tropics but stratocumulus. An application of the findings of this exploratory study of the wider tropics is left for future research.

Section 2 describes the data sources used and the methodology for combining them. Section 3 establishes the relation of the tropical ISCCP regimes to TRMMderived precipitation and provides a description of the precipitation characteristics of each regime. The information gathered is then used to better understand the geographic distribution of precipitation in the TWP. Section 4 studies the vertical structure of latent heating in each of the regimes and establishes the contributions of each of the regimes to the long-term mean latent heating in the TWP. Section 5 discusses the relevance of the findings of this study and future research avenues resulting from them, followed by concluding remarks in section 6 .

\section{Data sources}

\section{a. ISCCP-based cloud regimes}

This study uses the ISCCP-based cloud regimes derived by Rossow et al. (2005) to describe tropical weather states. Those regimes were derived by applying a cluster analysis to ISCCP joint histograms of cloudtop pressure (CTP) and cloud optical thickness $(\tau)$. The area and period covered were $15^{\circ} \mathrm{N}-15^{\circ} \mathrm{S}$ and July 1983-December 2001, respectively. In this study, the focus will be on the TWP region, defined as $10^{\circ} \mathrm{N}-10^{\circ} \mathrm{S}$, $130^{\circ}-170^{\circ} \mathrm{E}$. This region contains 128 ISCCP grid points, each representing an area of about $280 \times 280$ $\mathrm{km}^{2}$. Because these data will be matched with data from the TRMM satellite, the study period covers 1998-2003. Each of the ISCCP grid points in the TWP area is assigned to a regime for each day of the study period by finding the minimum Euclidian distance of its daytime mean CTP $-\tau$ histogram to the six tropical regime mean histograms defined in Rossow et al. (2005). Figure 1 shows the resulting 6-yr regime mean histograms for the TWP.

The regime mean histograms provide a characterization of the cloud fields associated with each regime based on the ISCCP retrievals. Characteristics of the regimes will be briefly summarized here. [Readers are referred to the studies of Jakob and Tselioudis (2003) and Rossow et al. (2005) for more information.] The first regime (Fig. 1, top left) is characterized by large amounts of optically thick clouds with high tops. This signature likely indicates large systems with significant stratiform cloud coverage [convectively active deep cloud (CD)].The $\mathrm{CD}$ regime occurs with a relative frequency of occurrence (RFO) of $15 \%$ over the TWP in the study period. The second regime (Fig. 1, top middle) also exhibits a significant amount of deep cloud (top right quadrant of the CTP- $\tau$ histogram), but the majority of the cloud occurrence is accounted for by optically thinner high-top clouds with CTP and $\tau$ values typically found in cirrus [convectively active cirrus (CC)]. The RFO of the CC regime is $11 \%$. The third regime (Fig. 1, top right) still exhibits a fair amount of deep convective cloud but in general, the CTP- $\tau$ distribution is fairly broad. This broadness can be interpreted as a mixture of different cloud types (MIX) in a convectively active region with no strong generation of large cirrus or anvil clouds. MIX is the most common regime in the TWP $(\mathrm{RFO}=33 \%)$.

The remaining three regimes have been identified as largely convectively suppressed because of the small frequency of occurrence of thick high-top clouds. The first of these regimes (Fig. 1, bottom left) is dominated by large amounts of very thin cirrus [suppressed thin cirrus (STC)]. The STC regime has an RFO of $14 \%$. It is worth noting that the separation of the STC and MIX regimes in this TWP-only study is weaker than that found for the entire tropics in Rossow et al. (2005). This may explain why the earlier TWP-only study by Jakob and Tselioudis (2003) did not identify the MIX regime at all. The second and most frequent $(\mathrm{RFO}=25 \%)$ suppressed regime (Fig. 1, bottom middle) is dominated by shallow clouds with low coverage and low optical thickness, most likely trade cumuli [suppressed shallow cloud with low coverage (SSCL)] The SSCL regime is distinct from the final suppressed regime (Fig. 1, bottom right), which also shows a predominance of low clouds but with much higher areal coverage and optical thickness. This third regime is likely a stratocumulus regime [suppressed shallow cloud with high coverage $(\mathrm{SSCH})]$. The SSCH regime is very rare in the TWP $(\mathrm{RFO}=2 \%)$.

Before combining the ISCCP regime information with precipitation characteristics derived from TRMM, it is worth presenting the geographic distribution of the occurrence of each of the regimes in the TWP, which is summarized in Fig. 2. The deep convective regimes (CD and $\mathrm{CC}$; top panels) occur relatively infrequently. The higher occurrence of both the $\mathrm{CD}$ and $\mathrm{CC}$ regimes markedly follows the outline of the warmest SSTs. Both 

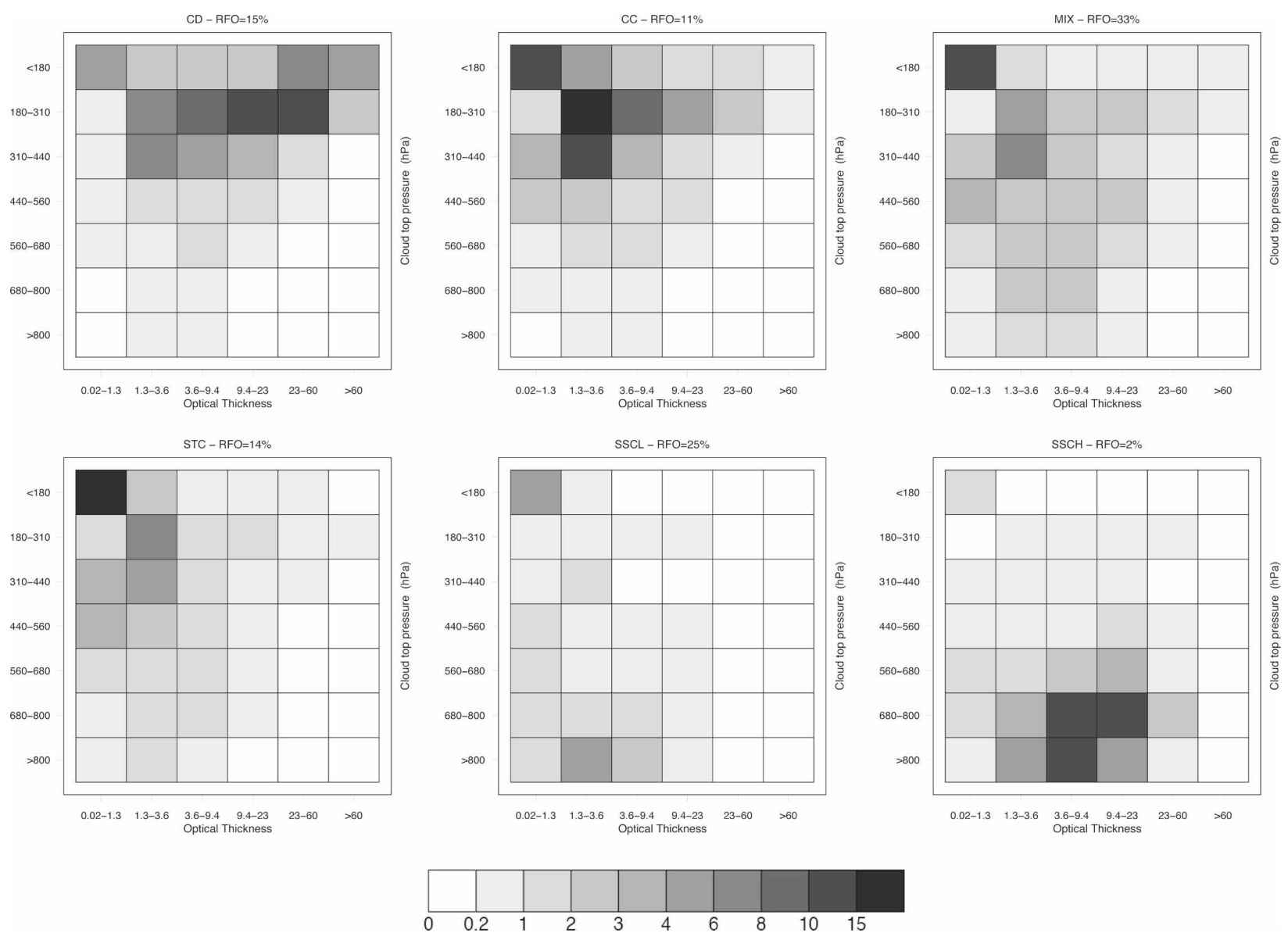

FIG. 1. Mean CTP- $\tau$ frequency distributions (\%) for the six tropical ISCCP cloud regimes averaged for the TWP for 1998-2003.

regimes are less likely to occur over land and over the colder equatorial SSTs in the eastern part of the domain. The most frequently occurring regimes are MIX and SSCL. Figure 2 reveals that they occur in quite separate geographic regions. The (presumably) more convectively active MIX regime shows relative maxima over the island of New Guinea (NG) and over the ocean in the extension of the ITCZ in the northeastern part of the domain. The land maximum has to be interpreted with caution for a number of reasons. The daytime-only character of the ISCCP data limits its usefulness in land regions with strong diurnal variations. In addition, NG has significant orography. Because the vertical coordinate in the ISCCP analysis is pressure, low clouds overlying high mountains can easily be interpreted as midlevel top clouds, which feature prominently in the MIX regime. For these reasons, we considered removing land from the rest of the analysis but only 6 of the 128 grid points in the study area are fully covered by land and, therefore, they do not greatly influence the overall statistics. However, it needs to be stressed that when geographic distributions are shown, the interpretation of the results over land ought to be treated cautiously. The SSCL regime is also widespread in comparison to the active $\mathrm{CC}$ and $\mathrm{CD}$ regimes. As shown by Rossow et al. (2005), this regime typifies suppressed trade cumulus conditions. Therefore, it is no surprise to see its maxima of occurrence over the relatively colder equatorial SSTs in the eastern part of the domain.

The STC regime (Fig. 2, middle right) occurs predominantly between the active branches of the ITCZ seen in the $\mathrm{CD}$ regime. This pattern might indicate an important role of the convectively active regions in generating the conditions in which thin cirrus can be prevalent away from the convection itself. The SSCH regime (Fig. 2, bottom right) is extremely rare in the study area, with a single maximum of occurrence at the southern tip of NG. While certainly interesting, the rarity of this regime makes it impossible to study in the region chosen here so the regime will be omitted from further analysis. 

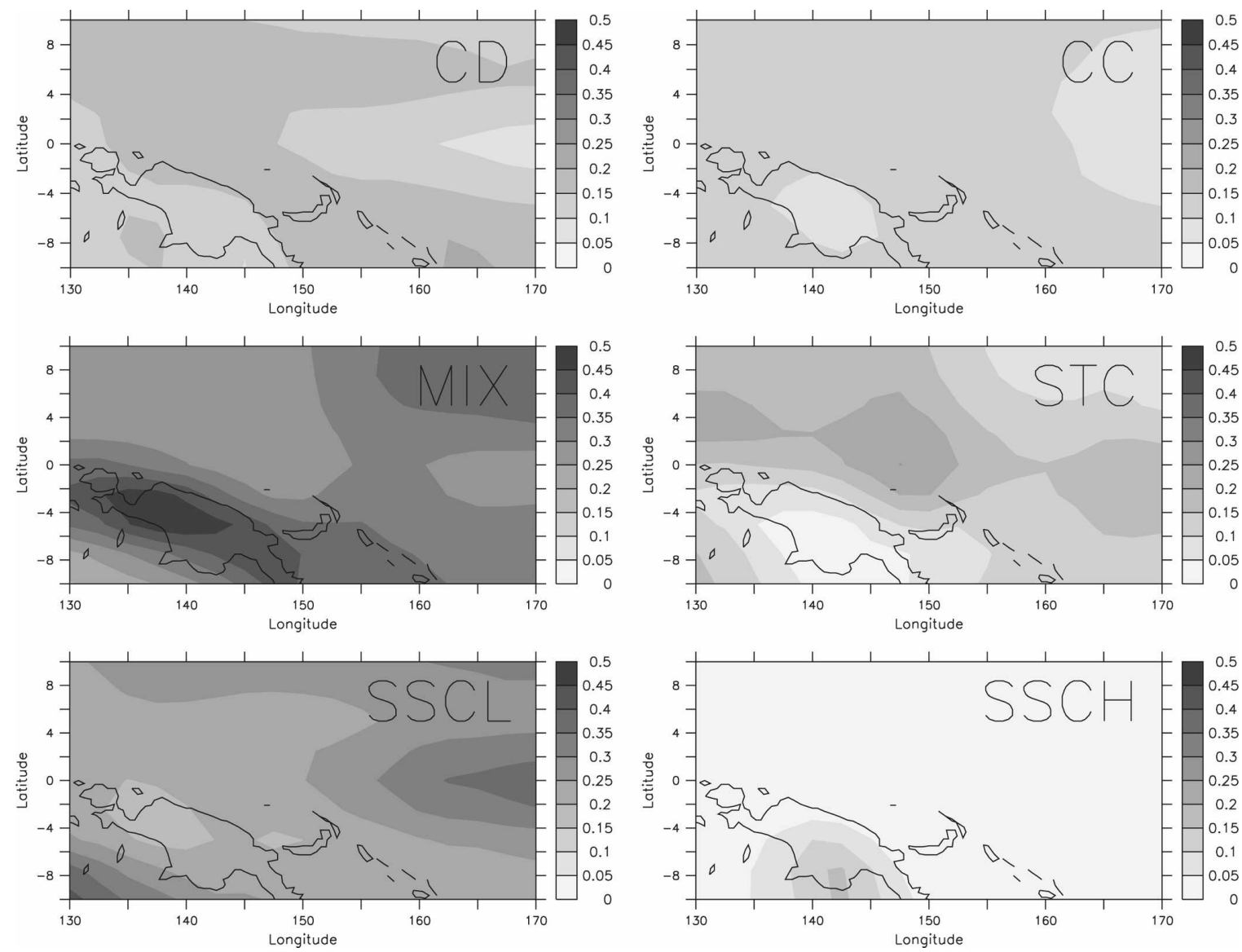

FIG. 2. Relative frequency of occurrence of the six tropical ISCCP cloud regimes in the TWP area for 1998-2003.

\section{b. TRMM precipitation radar data and algorithms}

This study uses observations from 1998 to 2003 from the precipitation radar (PR) onboard the TRMM satellite. From January 1998 to August 2001, the PR had a swath width of $215 \mathrm{~km}$ and a horizontal footprint of 4.3 $\mathrm{km}$ at nadir. The satellite was boosted to a higher altitude in August 2001 to conserve fuel, after which the PR had a swath width of $240 \mathrm{~km}$ and a footprint of $5 \mathrm{~km}$ at nadir. The vertical resolution of the PR remained 250 $\mathrm{m}$ at nadir. The PR operates at $\mathrm{Ku}$ band $(2.17-\mathrm{cm}$ wavelength) with a sensitivity $17-\mathrm{dB} Z$ preboost and $18-\mathrm{dB} Z$ postboost, which corresponds to a rain rate of approximately $0.4-0.5 \mathrm{~mm} \mathrm{~h}^{-1}$. Shimizu et al. (2003) showed that besides the expected postboost degradation in sensitivity of $1.2 \mathrm{~dB}$, there were no other significant discontinuities in PR observations at the time of the boost. In addition, the TRMM satellite has a precessing orbit so it samples the full diurnal cycle within a 47-day period. Further details on the PR and the TRMM satellite can be found in Kummerow et al. (1998) and Kozu et al. (2001).

The radar echo observed by the PR is subdivided into convective and stratiform rain types in TRMM product 2A23 (Awaka et al. 1997). The convective classification refers to areas of young, active convection where stronger vertical air motions predominate and precipitation particles increase in mass through coalescence and/or riming (Houze 1993). The stratiform classification represents areas where weaker vertical air motions predominate and precipitation particles increase in mass primarily through vapor deposition above the $0^{\circ} \mathrm{C}$ level and decrease in mass through evaporation below the $0^{\circ} \mathrm{C}$ level. Echo is classified as convective if it has a reflectivity of at least $39 \mathrm{dBZ}$ at low levels or if it shows a strongly peaked reflectivity from surrounding pixels. Echo is classified as stratiform if a bright band is present or if it has more horizontally homogeneous near-surface reflectivities. It is labeled as shallow isolated (hereafter shallow) when its top is at least $1 \mathrm{~km}$ below the $0^{\circ} \mathrm{C}$ level, and it is not attached to deeper echo. This echo category is considered shallow convective because it most likely represents only warm rain processes (Schumacher and Houze 2003b).

For each rain type, attenuation-corrected reflectivity observations from TRMM product 2A25 (Iguchi et al. 
2000) were categorized by height (500-m increments from 1 to $15 \mathrm{~km}$ ) and reflectivity (2- $\mathrm{dB} Z$ bins from 16 to $60 \mathrm{dBZ}$ ) at $2.5^{\circ} \times 2.5^{\circ}$ resolution in daily files. The resulting histograms have 28 latitude bins, 144 longitude bins, 28 height bins, and 23 reflectivity bins. Note that the daily histograms are composed of data from only 1-2 overpasses and that each overpass will only cover part of the grid box. Our analysis is based on histograms compiled from the version 5 (V5) orbital data mined by the TRMM Science Data and Information System (TSDIS). Although version 6 (V6) introduced some significant changes to the PR's rain profiling algorithm, oceanic reflectivity distributions (the raw material for our calculations) remain similar between V5 and V6. In addition, the PR rain-type algorithm experienced relatively small modifications. Therefore, the following results should not be overly sensitive to a change in dataset version.

The daily PR reflectivity histograms were matched to the ISCCP regimes existing in the $2.5^{\circ} \times 2.5^{\circ}$ box each day from 1998 to 2003. There is a small geographical offset between the TRMM PR and ISCCP grids, but the effect of the offset is small. In addition, the PR observations can be from any time of day, whereas the ISCCP regimes are only classified for daylight observations. However, the ISCCP regimes tend to have persistence on the order of a day (Jakob et al. 2005), which limits sampling error from temporal offsets. Finally, because of the relatively narrow swath of the TRMM PR, not all daily ISCCP grid points contain PR observations. After matching the ISCCP and TRMM datasets, the total number of available samples is slightly more than 155000 (compared to a possible 280000 ). With this large overall sample size, all regimes apart from the omitted SSCH regime are well described, with the smallest regime sample (CC) containing about 17800 matching daily grids. The final PR histograms represent the cumulative reflectivity distributions for each cloud regime over the 6-yr period of interest.

The binned reflectivity at $2-\mathrm{km}$ altitude for each cloud regime was then converted to rain rate using initial TRMM convective and stratiform near-surface reflectivity rain-rate $(Z-R)$ relations $\left(Z=148 R^{1.55}\right.$ and $Z=276 R^{1.49}$, respectively). The convective $Z-R$ relation was also applied to the shallow echo distribution. The 6-yr average convective, stratiform, and shallow rain rate in each grid box was then multiplied by the probability of rain for each rain type and the number of hours in the 6-yr period to obtain the deep convective, stratiform, and shallow convective rain amounts. These rain amounts were used as inputs in estimating the latent heating profile for each regime (see Schumacher et al. 2004 for more details on the latent heating calcula- tion). The choice of $Z-R$ relation(s) could have an impact on the relative contributions of convective and stratiform rainfall and the resulting latent heating profiles. However, based on sensitivity tests performed in Schumacher and Houze (2003a), we expect the impact to be small, especially when comparing rain rates and latent heating profiles between regimes.

\section{Surface precipitation characteristics of the TWP ISCCP cloud regimes}

Having identified the ISCCP-based cloud regimes and matched them with TRMM PR observations on a daily basis for each TWP grid point, the precipitation characteristics of each ISCCP regime in the TWP can be described in a statistical sense for the 6-yr period. The first precipitation characteristic to be analyzed is the fractional area coverage in a grid box $\left(2.5^{\circ} \times 2.5^{\circ}\right)$ with the three main TRMM precipitation types, that is, deep convective, stratiform, and shallow convective. This fraction is calculated by dividing the number of PR pixels identified in a rain-type category by the total number of PR pixels in a grid box, including those classified as nonprecipitating. These calculated daily mean gridbox area fractions are matched with the daily ISCCP-based regimes to arrive at rain-type frequency distributions for each cloud regime (Fig. 3). The numbers in each panel indicate the regime sample size. Median deep convective precipitation area fractions (Fig. 3 , left) are below 0.02 for all regimes. They are largest for the CD regime and smallest for the SSCL regime, with the other three regimes showing intermediate values. In all regimes the frequency distributions are skewed, with long tails toward larger fractions. The largest fractions are exhibited by the $\mathrm{CD}$ regime with values close to 0.1 near the 95 th percentile. The convective precipitation area fractions in Fig. 3 are highly consistent with the convective areas observed by aircraft in the west Pacific during the Tropical Ocean and Global Atmosphere Coupled Ocean-Atmosphere Response Experiment (TOGA COARE; Yuter and Houze 1998).

The CD regime displays the largest stratiform precipitation area fraction of all the regimes (Fig. 3, middle). The median $\mathrm{CD}$ value is near 0.1 , more than twice that of any other regime. The $\mathrm{CD}$ regime differs even more from the others in its above-median values. Over $25 \%$ of the samples in this regime show a stratiform precipitation area fraction of greater than 0.2 , and the 95th percentile lies around the 0.5 fractional area coverage. The CC, MIX, and STC regimes again show strong similarities among each other but have significantly lower stratiform precipitation area fractions than the $\mathrm{CD}$ regime. Typical median values are below 0.05 , 

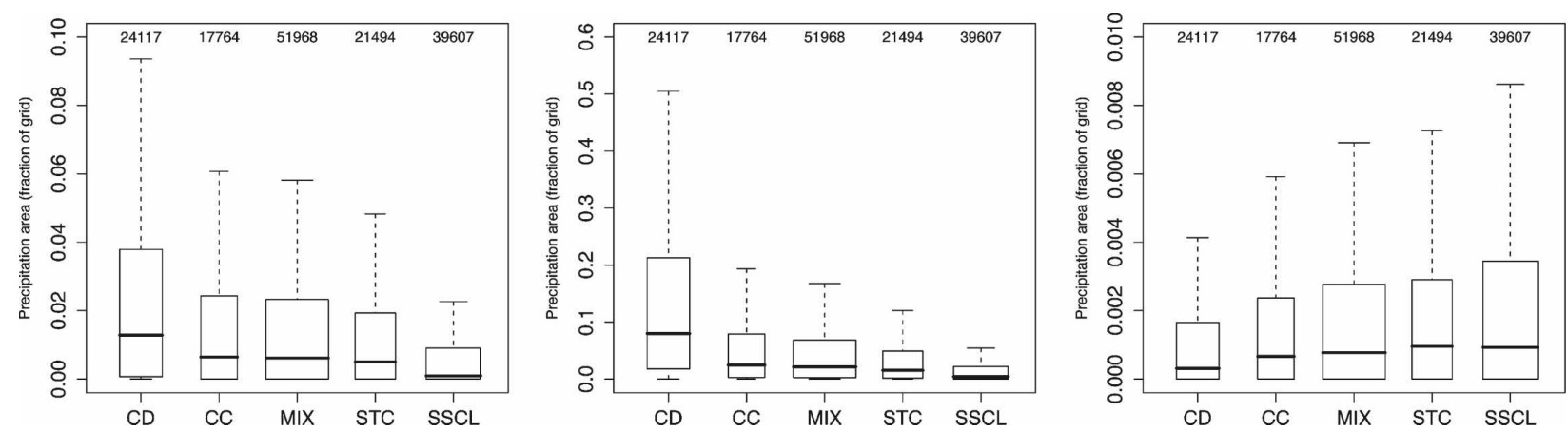

FIG. 3. Precipitation area fraction (fraction of grid) of (left) deep convective, (middle) stratiform, and (right) shallow convective precipitation for each ISCCP cloud regime. Boxes represent the 25th-75th percentiles; whiskers represent the 5th-95th percentiles of the frequency distribution. The box width is proportional to the sample size, which is also displayed at the top of each panel.

and the 75th percentile for these regimes does not exceed 0.1 , which is the median value for the $\mathrm{CD}$ regime. The smallest stratiform precipitation coverage is found in the SSCL regime with a median close to zero, with few values above 0.1 . The distribution of stratiform precipitation areas observed by Yuter and Houze (1998) during TOGA COARE is generally consistent with this study; however, the values in Fig. 3 are lower than those reported by Yuter and Houze. The two likely reasons for this difference are that the aircraft missions during TOGA COARE preferentially sampled large mesoscale convective systems, and the sensitivity of the PR limits its ability to sense large regions of weak echo, $<17 \mathrm{dBZ}$, associated with stratiform rain. Schumacher and Houze (2000) noted that the PR missed $<3 \%$ of near-surface rain observed by a ground radar on Kwajalein in the Marshall Islands, but it missed $45 \%$ of near-surface rain area. Thus, the stratiform precipitation area fractions in Fig. 3 are applicable for comparisons between regimes, but the absolute values are potentially underestimated by up to a factor of 2 .

The shallow isolated precipitation category exhibits very small area coverage across all the regimes. The area coverage by shallow convective precipitation increases steadily from CD to SSCL regimes. Median, 75th, and 95th percentile values in the SSCL regime are roughly double those of the $\mathrm{CD}$ regime, with the other regimes falling in between. Even in the SSCL regime, there are only a few values greater than 0.01 . The low area coverage in the shallow category is not surprising because shallow precipitation tends to occur in regions with low cloud fraction, such as trade cumulus, in which only a small fraction of clouds tends to precipitate. The 4.3-5-km footprint and 17-18- $\mathrm{dBZ}$ sensitivity threshold of the TRMM radar will also likely lead to an undersampling of shallow convective precipitation because shallow isolated cells tend to be smaller than the PR's footprint with weak reflectivity.
Figure 4 displays the regime- and grid-box averaged daily precipitation and its stratification into the deep convective, stratiform, and shallow convective precipitation categories. The largest within-regime daily rainfall amounts are associated with the $\mathrm{CD}$ regime at nearly $12 \mathrm{~mm} \mathrm{day}^{-1}$. The CC and MIX regimes exhibit daily rainfall rates of less than half that of the $\mathrm{CD}$ regime $\left(\sim 5.5 \mathrm{~mm} \mathrm{day}^{-1}\right)$. The lowest rain rates are found in the suppressed STC $\left(\sim 4 \mathrm{~mm} \mathrm{day}^{-1}\right)$ and SSCL $(\sim 2.3$ $\mathrm{mm}$ day $^{-1}$ ) regimes. In addition to the amount of precipitation, the $\mathrm{CD}$ regime is the only regime in which the stratiform rain amount dominates precipitation, with a split of $54 \%$ stratiform to $44 \%$ deep convective (the residual $2 \%$ resides in the shallow component). The precipitation amounts in all other regimes are

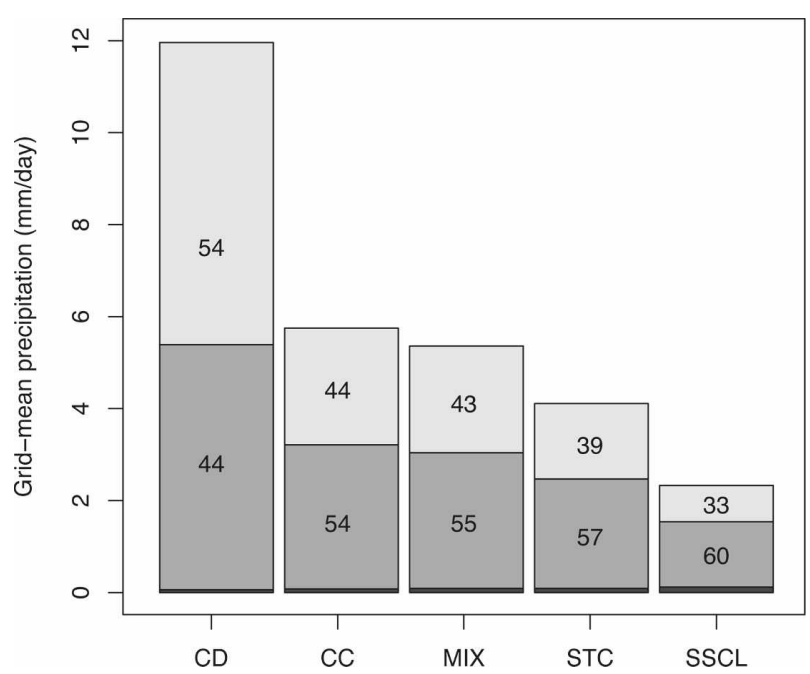

FIG. 4. Surface gridbox average rain rates $\left(\mathrm{mm} \mathrm{day}^{-1}\right)$ for each ISCCP cloud regime. Bar shading indicates precipitation category: shallow convective (black), deep convective (dark gray), and stratiform (light gray). The numbers displayed in the bars are the percentage fraction of the total rain for the (top) stratiform and (bottom) deep convective component. 
dominated by the deep convective component. The dominance of this component increases gradually from $54 \%$ in the CC regime to $60 \%$ in the SSCL regime. At the same time, the stratiform contribution reduces from $44 \%$ in the CC regime to $33 \%$ in the SSCL regime. The only significant contribution to rainfall from shallow convective precipitation occurs in the SSCL regime, where $7 \%$ of the rainfall comes from shallow isolated cells. The rainfall amounts discussed above confirm in broad terms the earlier finding from area fraction statistics that the five ISCCP-based cloud regimes fall into three broad precipitation categories.

To gain further insight into the precipitation characteristics of the cloud regimes and to begin evaluating their relative contribution to the overall distribution of precipitation by rain type (deep convective, stratiform, and shallow convective), it is worthwhile to examine some of the relationships between different precipitation characteristics found by Schumacher and Houze (2003a, their Figs. 5 and 6) by ISCCP-based cloud regimes. For this purpose, scatterplots of stratiform rain fraction (the amount of stratiform precipitation divided by total precipitation) versus stratiform area fraction (the area of stratiform precipitation divided by total precipitation area), rain accumulation, and convective and stratiform rain rates are shown in Fig. 5. The figure is constructed in the following way: the mean precipitation characteristics for each regime's grid point are calculated for each of the 128 grid boxes in the study area. To ensure sufficient sampling, a minimum of 9000 raining PR pixels per regime at a given grid point within the 6-yr study period was required. This threshold excluded 20 grid boxes for the STC regime in the vicinity of $\mathrm{NG}$, where the regime shows a very low frequency of occurrence (cf. Fig. 2). Therefore, each regime, with the exception of STC, contributes 128 points to each scatterplot (108 in the case of STC). Points contributed by the different regimes are indicated by different colors. Horizontal and vertical lines denote average TWP values.

As in earlier studies (cf. Schumacher and Houze 2003a) stratiform rain fraction is well correlated with stratiform area fraction (Fig. 5, top left). Note that the definition of stratiform area fraction here differs from that of the gridbox area fractions shown in Fig. 3, which represented the percent of the grid covered by a certain rain type. Stratiform area fractions in Fig. 5 range 55\%$90 \%$ with stratiform rain fraction varying $20 \%-70 \%$. The relationship appears near linear, especially for below-average fractions. The data distribute well by ISCCPbased cloud regime, in particular at high and low values, which are dominated by the CD and SSCL regimes, respectively. Intermediate values are populated by the other three ISCCP regimes, with a small tendency for the STC regime to lie in the transition region from SSCL to MIX and CC. This strong separation of the data by regime underlines the potential usefulness of the ISCCP-based regime definition for furthering the understanding of tropical cloud and precipitation systems and their interaction with the large-scale circulation. This will be further discussed in section 5 .

Next, the conditional convective and stratiform rain rates, that is, the amount of rain falling in each rain type when it is raining will be investigated. Figure 5 (bottom) shows the deep convective (left) and stratiform (right) rain rates as a function of stratiform rain fraction delineated by regime. Increasing convective rain rates are generally associated with increasing stratiform rain fractions, although there is some scatter in that relationship. Somewhat counterintuitively, this indicates that as deep convection rains more heavily, an increasingly larger percentage of the total rain falls in the stratiform region. Stratiform rain rate also increases with an increasing stratiform rain fraction. Thus, large stratiform rain fractions are likely the result of both larger stratiform area fractions and higher stratiform rain rates. Interestingly the ISCCP-based regimes separate reasonably strongly by rain rates. The $\mathrm{CD}$ regime shows the highest deep convective and stratiform rain rates on average ( 8.8 and $1.9 \mathrm{~mm} \mathrm{~h}^{-1}$, respectively), whereas the SSCL regime shows the lowest on average ( 6.9 and $1.5 \mathrm{~mm} \mathrm{~h}^{-1}$ ), with the higher rain-rate outliers located over NG. These outliers suggest that some of the ISCCP regimes may have different precipitation characteristics over land. While the CD and SSCL regimes populate exclusive areas in the phase space of the rain-rate diagrams, the STC, MIX, and CC regimes show strong overlap in the intermediate rain-rate range.

The final relationship with stratiform rain fraction examined in Fig. 5 is the total grid-mean rain accumulation (top right). The rain accumulation is calculated as the total mean precipitation over the 6 years of the study that a regime contributes at a grid point, expressed in $\mathrm{mm} \mathrm{day}^{-1}$. This measure gives an indication of the overall importance of a regime to precipitation in the TWP region. As is evident from Fig. 5, two regimes contribute predominantly to precipitation in the TWP, namely the CD and the MIX regimes. They are the only two regimes showing contributions larger that $1 \mathrm{~mm}$ day $^{-1}$ at almost all grid points, whereas the other regimes rarely exceed that threshold. It is also evident that the "physics" of precipitation between the two important regimes is very different; the $\mathrm{CD}$ regime shows very large stratiform rain fractions, whereas those in the MIX regime are generally below average. This has 

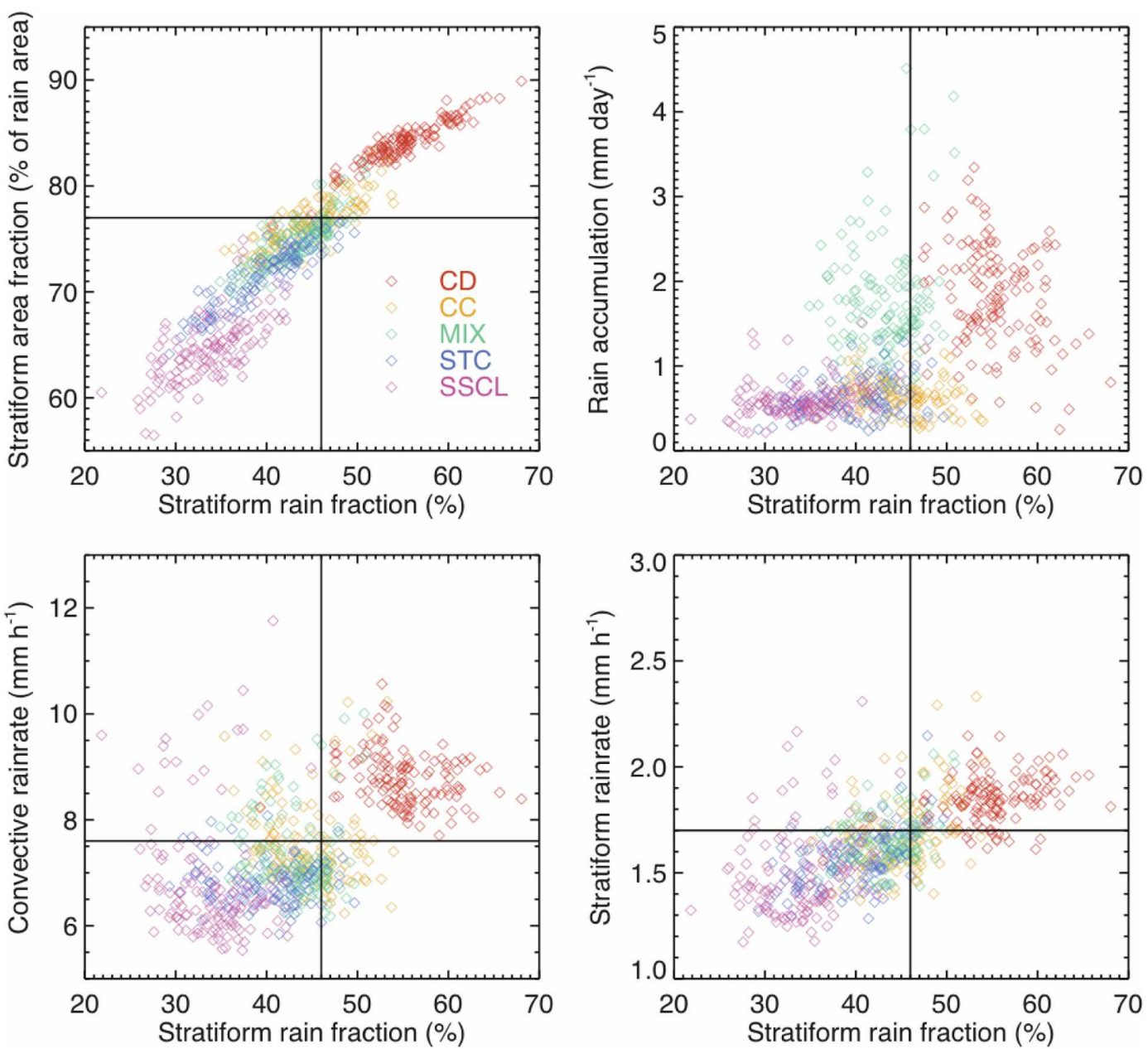

FIG. 5. The percent of total rain that is stratiform vs the percent of rain area that is (top left) stratiform, (top right) total rain amount, and (bottom left) conditional deep convective, and (bottom right) stratiform rain rates for each $2.5^{\circ} \times 2.5^{\circ}$ grid in the study domain, separated by regime for 1998-2003. Solid lines indicate average TWP values (refer to text for more detail).

clear implications for the latent heating characteristics of the two regimes, which will be further investigated in the next section.

Having established the contribution each regime makes to TWP precipitation, it is worthwhile to examine the spatial distribution of that contribution. This expands the findings in Fig. 5 (top right) geographically and enables further insight into the mean distributions of convective and stratiform precipitation derived in Schumacher and Houze (2003a). Figure 6 shows the spatial distribution of the deep convective and stratiform precipitation in the TWP (top panels) and the precipitation distributions by regime. For both rain types, precipitation is at the maximum in the ITCZ regions north and south of the equator and over NG. In the northern ITCZ, convective and stratiform precipitation contribute roughly equally to the total, while south of the equator, the convective component dominates. Can the regime separation shine more light on the reasons for this difference?

As was apparent in Fig. 5, the CD and MIX regimes make the largest contributions to TWP precipitation but for very different reasons. The $\mathrm{CD}$ regime occurs relatively infrequently (cf. Fig. 2), but it produces large amounts of precipitation with a large stratiform component (cf. Fig. 4). The MIX regime, on the other hand, produces less precipitation when present, but it occurs more frequently. The main difference between the precipitation behavior north and south of the equator can, therefore, be interpreted as a difference in regime occurrence, with the MIX regime dominating south of the equator (especially in the convective rain field), whereas the $\mathrm{CD}$ regime has a more significant influence to the north. One exception to this north-south differ- 


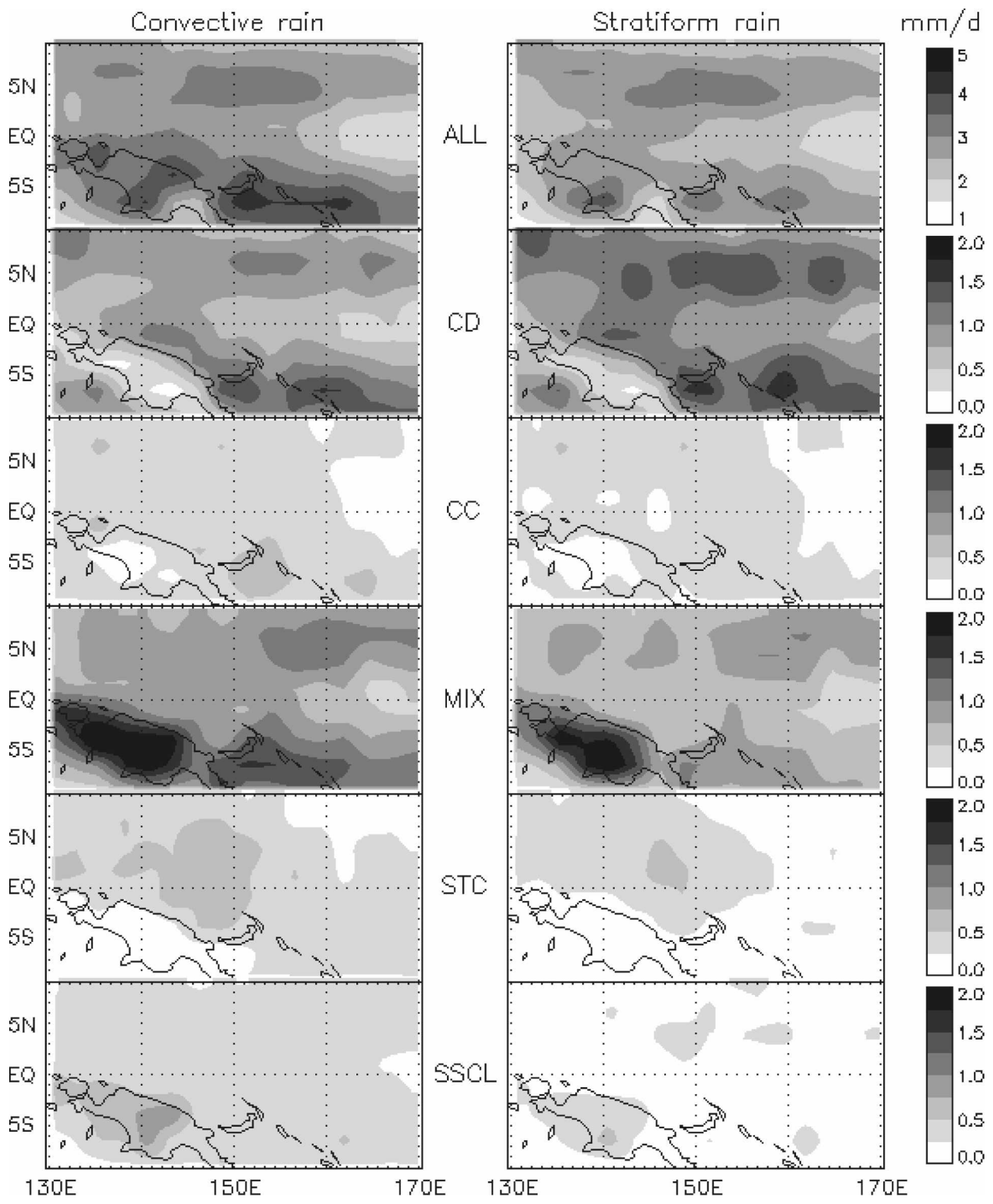

FIG. 6. (left) Convective and (right) stratiform precipitation averaged for (top) all of 1998-2003 and by regime.

ence is the large rain accumulations seen just north of NG in the CD regime. It is possible that this pattern represents the diurnal northward propagation of maturing convective systems off the coast of NG (Liberti et al. 2001).

Although the CD and MIX regimes account for twothirds of the precipitation in the TWP, the other three regimes each contribute roughly equally to the remaining third. The CC regime also makes a small but noticeable contribution to the north-south difference by exhibiting a maximum in mostly convective precipitation east of NG. Also noteworthy is the widespread character of the rainfall contribution of CC and STC over the ocean, and the dominance of the MIX and, to some extent, the SSCL in the precipitation over NG. As discussed earlier, the results over land have to be interpreted with great caution because of the daytime-only averaging and the ambiguous regime definition over orography. The SSCL rain pattern is very different from the SSCL RFO pattern in Fig. 2. In particular, the 
relatively high amounts of shallow cumulus over cooler SST regions do not produce much rain.

\section{The vertical structure of precipitation and latent heating of the TWP ISCCP cloud regimes}

The previous section discussed the surface precipitation characteristics of the ISCCP-based cloud regimes and elucidated their relative contribution to total rainfall in the TWP. The aim of this section is to extend the results at the surface to the vertical structure of the precipitation signatures of the ISCCP regimes as well as their latent heating structure based on TRMM PR data.

Figure 7 shows the distribution of radar echo tops within each regime (left panels) and for the entire TWP region, taking into account regime RFO (right panels) for deep convective (top), stratiform (middle), and shallow convective (bottom) precipitation. The withinregime profiles of echo top represent the number of echo tops identified in $0.5-\mathrm{km}$ height bins in a particular regime normalized by the total number of PR pixels (both precipitating and nonprecipitating) that were observed in that regime. The TWP-wide values represent the echo top counts within a regime normalized by the total number of PR pixels across all regimes.

In the within-regime distribution of convective echo tops (top left), it is evident that the $\mathrm{CD}$ regime shows the largest echo coverage and the highest tops. The peak of echo height occurrence in this regime is at about $6-7 \mathrm{~km}$ with a fairly broad distribution up to heights of $10 \mathrm{~km}$. The deeper convection is likely a factor in the larger convective rain rates observed in this regime. The CC and MIX regimes are very similar to one another with peaks at about $6 \mathrm{~km}$. The STC regime shows a transition to fewer convective echoes with even lower tops. The SSCL regime shows the least convective echo tops with a broad peak between 4 and $6 \mathrm{~km}$. Once normalized with regime RFO, the largest contribution to deep convective echo in the TWP is made by the MIX regime, followed by the CD regime. The distinct difference in echo top height between the two regimes is less obvious than in the within-regime figure; however, the MIX regime shows relatively more low convective echo tops. Furthermore, the CD regime still shows a preference for higher peaks than any of the other regimes. The CC, STC, and SSCL regimes contribute very similar amounts to TWP convective echoes, with the SSCL regime contributing slightly more low echo tops than the three other regimes.

Within-regime stratiform echo coverage is largest in the $\mathrm{CD}$ regime with a strong peak around $6 \mathrm{~km}$, which is just above the melting layer and the radar brightband region. It should be noted that weaker echo and cloud exist many kilometers above this height in stratiform rain regions. The drop-off in frequency is likely the result of the lack of sensitivity of the TRMM PR to the smaller particles aloft because the ISCCP histograms for the CD regime (cf. Fig. 1) show very large coverage with high-top clouds. All but the SSCL regime show a peak in echo frequency between 5-6 km, albeit with an overall much smaller frequency. Once normalized by regime $\mathrm{RFO}$, the $\mathrm{CD}$ regime still makes the largest contribution to stratiform echo in the TWP region, but the contribution from the MIX regime is also significant (albeit with fewer high echo tops). All other regimes make only a small contribution to stratiform rain occurrence.

Within-regime shallow convective echo top frequency shows a consistent peak near $3 \mathrm{~km}$ and is dominated by the SSCL regime. After normalization with regime RFO, the SSCL and MIX regimes contribute similar amounts to shallow echo coverage in the TWP. This indicates that both of these regimes contain shallow precipitating cumulus clouds consistent with their cloud-top distribution, as revealed by the ISCCP CTP $-\tau$ histograms (cf. Fig. 1).

Readers may have noted that some echo tops in the deep convective and stratiform distributions are less than $4 \mathrm{~km}$, and they may be considered shallow by the TRMM PR rain-type algorithm. However, these echo tops represent convection that is attached to deeper convection, and they are considered shallow nonisolated in version 6 of TRMM product 2A23. Shallow nonisolated echo is often overlain by deeper cloud (Casey et al. 2007), making comparisons with ISCCPderived regimes unfeasible. Therefore, the shallow isolated classification was considered most representative of precipitating shallow cumulus, and the shallow nonisolated echoes were left in their respective deep convective and stratiform classifications.

With the different echo top distributions and rainfall amounts, it can be expected that the cloud regimes make different contributions to the profile of latent heating. Given the importance of the latter for the interaction of convection with the large-scale tropical circulation, it is worth estimating the latent heating profiles of each regime and the overall contribution each regime makes to TWP latent heating. For this purpose, the method of Schumacher et al. (2004) is applied to each regime. The approach is to assume an idealized latent heating profile shape for each type of precipitation (deep convective, stratiform, and shallow convective), then use rain amount observations to determine the magnitude of the heating. For example, in a region with $50 \%$ deep convective and $50 \%$ stratiform rain, the idealized deep convective and stratiform heating pro- 

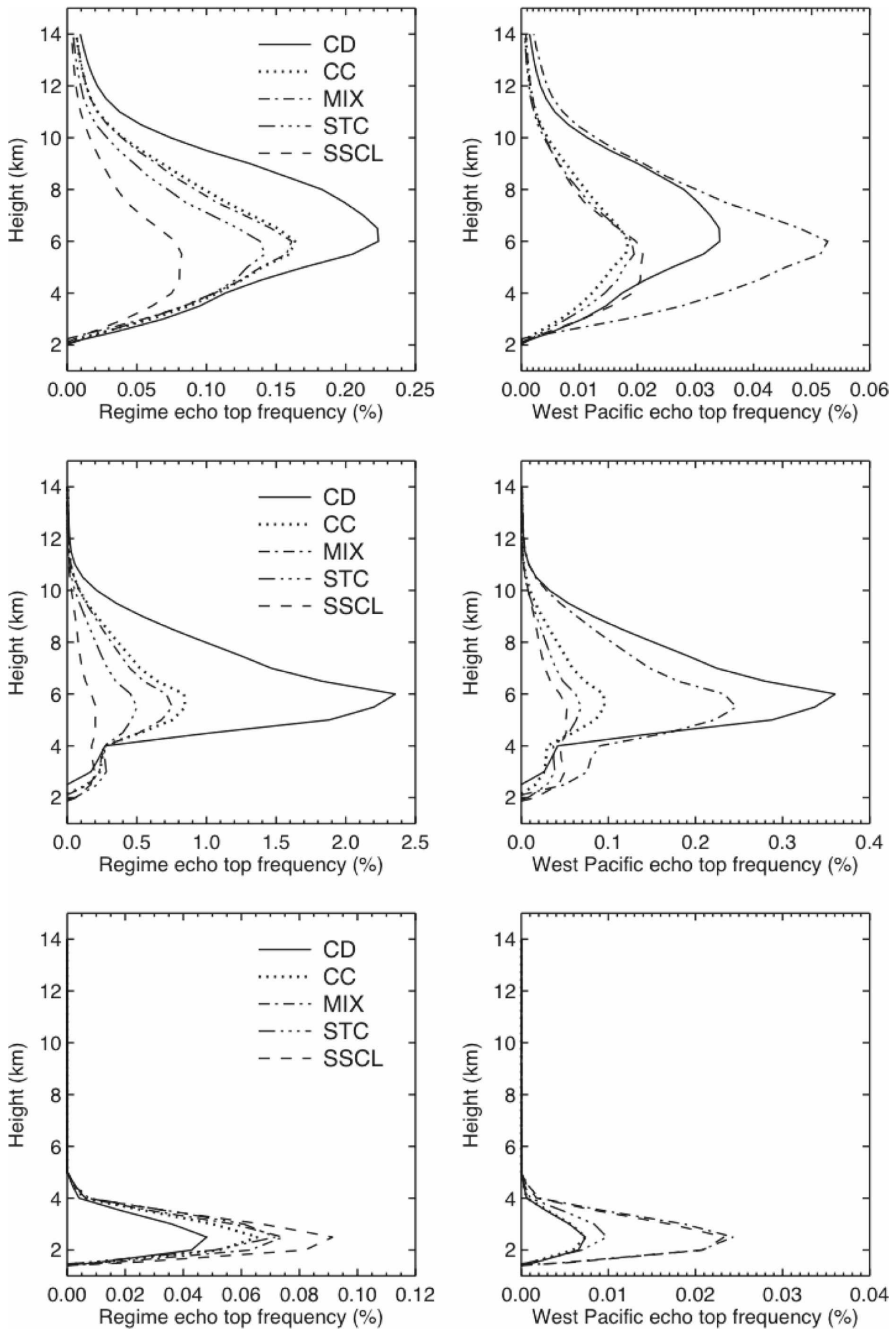

FIG. 7. Distribution of radar echo tops as a function of height (left) within each regime and (right) for the entire TWP region scaled by regime RFO for (top) deep convective, (middle) stratiform, and (bottom) shallow convective rainfall. 

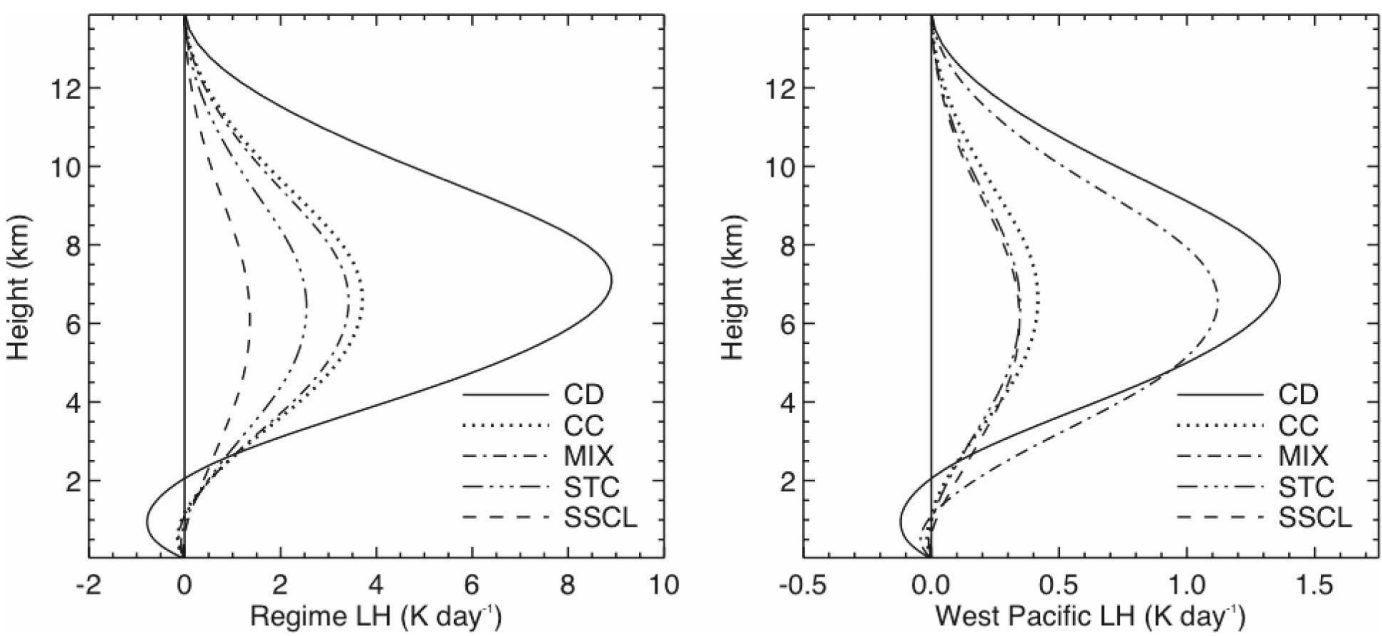

FIG. 8. (left) Within-regime and (right) TWP-averaged profiles of latent heating as a function of ISCCP-based cloud regime.

files would be averaged to obtain the appropriate vertical structure. The observed total rainfall would then be used to determine how much heating $\left(\mathrm{K} \mathrm{day}^{-1}\right)$ is actually occurring. It should be noted that this method does not account for the latent heating and cooling associated with nonprecipitating cumulus clouds, which may affect the distribution of latent heating at low levels. Figure 8 shows the within-regime and TWPaveraged profiles of latent heating for each cloud regime.

The earlier findings of this study translate well into the within-regime latent heating profiles (Fig. 8, left). The CD regime, the only regime dominated by stratiform precipitation, has the largest gridbox mean latent heating with a peak magnitude of almost $9 \mathrm{~K} \mathrm{day}^{-1}$ at around $7 \mathrm{~km}$. It is also the only regime with significant cooling below $2 \mathrm{~km}$, brought about by the evaporative cooling in the stratiform mode. All other regimes show profiles more typical of a convective mode with a bowshaped profile. The level of maximum heating in these regimes is lower than in the $\mathrm{CD}$ regime, and it decreases with decreasing convective activity. The $\mathrm{CC}$ and MIX regimes show peak heating of $3-4 \mathrm{~K} \mathrm{day}^{-1}$ at around $6.5 \mathrm{~km}$, which reduces to less than $2 \mathrm{~K}$ day $^{-1}$ at just below $6 \mathrm{~km}$ in the SSCL regime.

Having identified the within-regime latent heating characteristics, this knowledge can again be applied to elucidate the contribution of each regime to mean TWP latent heating. The CD and MIX regimes, as expected, dominate with peak heating of 1.4 and $1.1 \mathrm{~K}_{\text {day }}{ }^{-1}$, respectively. However, there are noticeable differences in the vertical structure of the heating in those two regimes. The $\mathrm{CD}$ regime peak occurs up to $1 \mathrm{~km}$ higher than in the MIX regime. Heating above about $5 \mathrm{~km}$ is significantly larger in the $\mathrm{CD}$ regime, owing to its large stratiform component. Below $5 \mathrm{~km}$, the MIX regime contributes larger heating rates with the $\mathrm{CD}$ regime showing cooling below about $2 \mathrm{~km}$. These vertical structure differences have potentially significant consequences for the interaction of these regimes with dynamical features of the tropics. In addition to differences in the vertical shape, Fig. 8 also reveals large differences in magnitude when present, with infrequent but strong heating due to the $\mathrm{CD}$ regime, and frequent but weak heating in the MIX regime. Each of the other three regimes (CC, STC, and SSCL) contribute much smaller amounts to latent heating in the TWP; although taken together, they have a similar magnitude to the $\mathrm{CD}$ and MIX regimes. The vertical shape of heating in these regimes is similar to the MIX regime, confirming their predominantly convective character. When all of the TWP regime latent heating profiles are summed, the resulting profile (not shown) is similar to the mean diabatic heating profile observed during TOGA COARE using sounding budgets (Lin and Johnson 1996, their Fig. 11).

\section{Discussion}

The combination of the ISCCP cloud regime information with TRMM PR precipitation and latent heating information has led to a number of interesting findings and potentially opens up new avenues for further research. Although the stratification of the data when distributing the TRMM information by ISCCP regime may seem obvious, the results in the previous sections are far from trivial and have implications for the ISCCP-based interpretation of tropical cloudiness. The 
ISCCP regimes have been derived by a simple statistical algorithm with no a priori information other than the daytime average CTP- $\tau$ histograms (Jakob and Tselioudis 2003; Rossow et al. 2005), yet early studies have revealed strong links between the ISCCP regimes and the Madden-Julian oscillation (MJO; e.g., Rossow et al. 2005; Höglund 2005). That independent data-TRMM in this case-stratify "sensibly" further highlights the potential for using the ISCCP regimes to better understand tropical weather and climate. For example, the separation of latent heating when using the ISCCP regimes provides opportunities for using the long-term global ISCCP information ( $>20 \mathrm{yr}$ ) as a proxy, enabling the construction of long-term datasets of latent heating. These in turn could be used in furthering our understanding of the interactions of the tropical circulation with convection or for constructing datasets for the evaluation of the representation of latent heating in GCMs.

This study has revealed that among the five ISCCP regimes used here, three major precipitation and latent heating "states" exist on the scale of $2.5^{\circ} \times 2.5^{\circ}$, with the $\mathrm{CD}$ regime representing the first; the $\mathrm{CC}$, MIX, and STC regimes representing the second; and the SSCL regime representing the third. An intriguing question resulting from this finding is whether it is an artifact of separation driven by the ISCCP regimes or whether at that scale nature does in fact produce such a small set of precipitation "regimes." Recent work by Caine et al. (2007, manuscript submitted to Mon. Wea. Rev.) has revealed four precipitation regimes in the Darwin region based on an objective classification of threedimensional radar images. When linking those four precipitation regimes to the same ISCCP-based regimes, they found a separation into three major precipitation states that are very similar to the ones revealed here. Note that the existence of only three precipitation regimes does not invalidate the larger number of regimes found in the ISCCP data. The latter are based on shortwave and infrared radiation information, and precipitation is only one of the many characteristics of the regimes. Jakob et al. (2005) have shown that other characteristics such as surface radiation or water vapor also distribute into a larger number of regimes.

Of the three precipitation states, only one (the CD regime) shows a dominance of stratiform over convective precipitation. It is well established (see references in the introduction) that systems with predominant stratiform heating interact strongly and differently from purely convective systems with the tropical circulation. Using the knowledge provided by this study, therefore, opens up opportunities for studying such interactions using the ISCCP-based regimes.
Several of the findings of this study could potentially also contribute to the development of models, in particular GCMs in which convection is a process acting on scales smaller than the grid size and hence requires parameterization. If the three precipitation/latent heat regimes found here are in fact the most typically occurring, this needs to be considered when constructing parameterizations. Current cumulus parameterizations distinguish between shallow and deep convection, and some recent efforts have been focused on including a third type to represent clouds of medium vertical extent (cumulus congestus). The results of this study indicate that, at least in the TWP, latent heating is in fact strongly influenced by a regime with significant stratiform components, a situation only poorly catered for in current parameterizations. It appears important to include this convection regime in existing models.

The results of this study provide an opportunity to examine if current models realistically simulate the latent heating characteristics of tropical convection. Through the use of the ISCCP simulator (Klein and Jakob 1999; Webb et al. 2001), it is possible to examine the ISCCP regimes in models (e.g., Williams and Tselioudis 2007). Once the model regimes have been determined, the model's latent heating structures can be stratified into them and the results compared to those here. This should reveal the model's ability to represent not only mean structures, but also the very important differences in magnitude and shape of the heating structures between regimes. This, combined with the further elucidation of the ISCCP regime-circulation interactions advocated above, might lead to a better understanding of well-documented long-term model flaws, such as the inability to simulate the MJO.

A very direct finding of this study is an improved understanding of the previously reported stratiform/ convective precipitation distribution in the tropics (e.g., Schumacher and Houze 2003a). It has been shown here that the ratio of the two components of precipitation is strongly regime dependent. With that information, it was possible to explain the difference in this ratio in the TWP north and south of the equator through a difference in the frequency of occurrence of the different cloud and convective regimes.

Because its focus was on establishing a methodology and evaluating its usefulness, this study has been limited to the TWP. Naturally, the conclusions that can be drawn for the precipitation behavior are limited to that region only. The overall success of establishing relationships between the ISCCP-based cloud regimes and TRMM precipitation information provides opportunities for an extension of the study to other regions of the tropics in future work. 


\section{Concluding remarks}

This study combined ISCCP-based information on tropical cloud mixtures with precipitation and latent heating profile estimates from the TRMM PR. The purpose of the study was twofold: 1) to investigate and describe the precipitation and latent heating characteristics of the cloud regimes, and 2) to use the knowledge acquired to better understand the observed distributions of convective and stratiform precipitation. This initial study was limited to the TWP region to mainly focus on the methodology of combining ISCCP and TRMM observations and to determine if there is any value in doing so. Despite the geographic limitation of the study, several important findings have resulted.

1) TRMM-derived precipitation and latent heating information stratifies well in the ISCCP-cloud regime space.

2) Within the five ISCCP regimes present, there are three major classes of precipitation characteristics: a strongly precipitating class dominated by the stratiform rainfall component represented by the $\mathrm{CD}$ regime; a moderately precipitating class dominated by the convective component represented by the CC, MIX, and STC regimes; and a weakly precipitating class represented by the SSCL regime.

3) Precipitation and latent heating in the TWP are dominated by two regimes with very different heating characteristics: the $\mathrm{CD}$ regime occurs relatively infrequently but with strong top-heavy latent heating profiles, and the MIX regime occurs frequently but with weaker, bow-shaped convective latent heating profiles.

4) The ISCCP CD regime is the only regime in which the stratiform precipitation component dominates the overall latent heating profile.

5) Much of the distribution of differences in the split between stratiform and convective precipitation in the TWP can be understood through differences in the frequency of occurrence of the ISCCP cloud regimes.

These findings raise a number of interesting questions for future research. An obvious extension is the application of the methodology developed here to the entire tropics to study if and in what way regional differences in precipitation and cloud regimes are associated with each other. One difficulty with such an extension lies in the application of the method over land. As alluded to earlier, the ISCCP data used for regime definition only exist during sunlit hours. Given the strong diurnal cycle over land, it is difficult to derive meaningful daily mean cloud regimes. This is compounded by the effects of orography. Nevertheless, extending the study to the entire tropics is an obvious next target. The finding that the CD regime is so outstanding, both in amount and shape of latent heating, implies that this regime warrants further investigation. Early indications show the $\mathrm{CD}$ regime to have very interesting associations with tropical circulations, such as monsoons and the MJO (e.g., Höglund 2005). One of the recently proposed stretched building blocks for tropical convection (Mapes et al. 2006) may also show a strong association with the $\mathrm{CD}$ regime. Future work will concentrate on providing some more insight into this particular regime. Other avenues opened by this study are the application of this technique for model evaluation of latent heating, and the extrapolation of information in space and time through the use of the statistical relationships between ISCCP regimes and latent heating. The study of tropical convection, its interaction with tropical dynamical features, and their representation in general circulation models remains at the forefront of unresolved problems in atmospheric science. This study has added an additional tool for addressing these problems.

Acknowledgments. We thank Bill Rossow and George Tselioudis at NASA GISS and Peter May at the Australian Bureau of Meteorology for interesting discussions about this study. We are grateful for the support from the U.S. Department of Energy under Grants DE-FG02-03ER63533, LANL-23662-001-013T, and DE-FG02-06ER64174 as part of the Atmospheric Radiation Measurement Program and from NASA New Investigator Program Grant NNX06AE23G. We thank two anonymous reviewers for their constructive comments.

\section{REFERENCES}

Ackerman, T. P., and G. M. Stokes, 2003: The Atmospheric Radiation Measurement Program. Phys. Today, 56, 38-44.

Awaka, J., T. Iguchi, H. Kumagai, and K. Okamoto, 1997: Rain type classification algorithm for the TRMM precipitation radar. Geosci. Remote Sens., 4, 1633-1635.

Casey, S., A. Dessler, and C. Schumacher, 2007: Frequency of tropical precipitating clouds as observed by the Tropical Rainfall Measuring Mission Precipitation Radar and ICESat/ Geoscience Laser Altimeter System. J. Geophys. Res., 112, D14215, doi:10.1029/2007JD008468.

Chiang, J. C. H., S. E. Zebiak, and M. A. Cane, 2001: Relative roles of elevated heating and surface temperature gradients in driving anomalous surface winds over tropical oceans. $J$. Atmos. Sci., 58, 1371-1394.

DeMaria, M., 1985: Linear response of a stratified tropical atmosphere to convective forcing. J. Atmos. Sci., 42, 1944-1959. 
Frank, W. M., H. Wang, and J. L. McBride, 1996: Rawinsonde budget analyses during the TOGA COARE IOP. J. Atmos. Sci., 53, 1761-1780.

Geisler, J. E., 1981: A linear model of the walker circulation. $J$. Atmos. Sci., 38, 1390-1400.

Hartmann, D. L., H. H. Hendon, and R. A. Houze Jr., 1984: Some implications of the mesoscale circulations in tropical cloud clusters for large-scale dynamics and climate. J. Atmos. Sci., 41, 113-121.

Höglund, S., 2005: Clouds in Darwin and their relation to largescale conditions. M.S. thesis, Dept. of Applied Physics and Mechanical Engineering/Physics, Lulea University of Technology, 52 pp. [Available online at http://epubl.ltu.se/14021617/2005/169/index-en.html.]

Houze, R. A., Jr., 1982: Cloud clusters and large-scale vertical motions in the tropics. J. Meteor. Soc. Japan, 60, 396-410.

— 1989: Observed structure of mesoscale convective systems and implications for large-scale heating. Quart. J. Roy. Meteor. Soc., 115, 425-461.

1993: Cloud Dynamics. Academic Press, 573 pp.

1997: Stratiform precipitation in regions of convection: A meteorological paradox? Bull. Amer. Meteor. Soc., 78, 2179 2196.

Iguchi, T., T. Kozu, R. Meneghini, J. Awaka, and K. Okamoto, 2000: Rain-profiling algorithm for the TRMM Precipitation Radar. J. Appl. Meteor., 39, 2038-2052.

Jakob, C., and G. Tselioudis, 2003: Objective identification of cloud regimes in the Tropical Western Pacific. Geophys. Res. Lett., 30, 2082, doi:10.1029/2003GL018367.

,-- , and T. Hume, 2005: The radiative, cloud, and thermodynamic properties of the major tropical western Pacific cloud regimes. J. Climate, 18, 1203-1215.

Johnson, R. H., 1984: Partitioning tropical heat and moisture budgets into cumulus and mesoscale components: Implications for cumulus parameterization. Mon. Wea. Rev., 112, 15901601.

Klein, S. A., and C. Jakob, 1999: Validation and sensitivities of frontal clouds simulated by the ECMWF model. Mon. Wea. Rev., 127, 2514-2531.

Kozu, T., and Coauthors, 2001: Development of precipitation radar onboard the Tropical Rainfall Measuring Mission (TRMM) satellite. IEEE Trans. Geosci. Remote Sens., 39, 102-116.

Kummerow, C., W. Barnes, T. Kozu, J. Shiue, and J. Simpson, 1998: The Tropical Rainfall Measuring Mission (TRMM) sensor package. J. Atmos. Oceanic Technol., 15, 809-817.

Liberti, G. L., F. Chéruy, and M. Debois, 2001: Land effect on the diurnal cycle of clouds over the TOGA COARE area, as observed from GMS IR data. Mon. Wea. Rev., 129, 15001517.

Lin, J., B. Mapes, M. Zhang, and M. Newman, 2004: Stratiform precipitation, vertical heating profiles, and the MaddenJulian oscillation. J. Atmos. Sci., 61, 296-309.

Lin, X., and R. H. Johnson, 1996: Heating, moistening, and rainfall over the western Pacific during TOGA COARE. $J$. Atmos. Sci., 53, 3367-3383.

Madden, R. A., and P. R. Julian, 1971: Detection of a 40-50 day oscillation in the zonal wind in the tropical Pacific. J. Atmos. Sci., 28, 702-708.

$\_$, and $\_$, 1972: Description of global-scale circulation cells in the tropics with a 40-50 day period. J. Atmos. Sci., 29, $1109-1123$.

Mapes, B. E., and R. A. Houze Jr., 1995: Diabatic divergence profiles in western Pacific mesoscale convective systems. $J$. Atmos. Sci., 52, 1807-1828.

- , S. Tulich, J. Lin, and P. Zuidema, 2006: The mesoscale convection life cycle: Building block or prototype for largescale tropical waves? Dyn. Atmos. Oceans, 42, 3-29.

McBride, J. L., B. W. Gunn, G. J. Holland, T. D. Keenan, N. E. Davidson, and W. M. Frank, 1989: Time series of total heating and moistening over the Gulf of Carpentaria radiosonde array during AMEX. Mon. Wea. Rev., 117, 2701-2713.

Nitta, T., and S. K. Esbensen, 1974: Heat and moisture budget analyses using BOMEX data. Mon. Wea. Rev., 102, 17-28.

Reed, R. J., and E. E. Recker, 1971: Structure and properties of synoptic-scale wave disturbances in the equatorial western Pacific. J. Atmos. Sci., 28, 1117-1133.

Rossow, W. B., and R. A. Schiffer, 1999: Advances in understanding clouds from ISCCP. Bull. Amer. Meteor. Soc., 80, 2261-2287.

- G. Tselioudis, A. Polak, and C. Jakob, 2005: Tropical climate described as a distribution of weather states indicated by distinct mesoscale cloud property mixtures. Geophys. Res. Lett., 32, L21812, doi:10.1029/2005GL024584.

Schiffer, R. A., and W. B. Rossow, 1983: The International Satellite Cloud Climatology Project (ISCCP): The first project of the World Climate Research Programme. Bull. Amer. Meteor. Soc., 64, 779-784.

Schumacher, C., and R. A. Houze Jr., 2000: Comparison of radar data from the TRMM satellite and Kwajalein oceanic validation site. J. Appl. Meteor., 39, 2151-2164.

_ and - 2003a: Stratiform rain in the tropics as seen by the TRMM Precipitation Radar. J. Climate, 16, 1739-1756.

$\longrightarrow$, and _ 2003b: The TRMM Precipitation Radar's view of shallow, isolated rain. J. Appl. Meteor., 42, 1519-1524.

- , - and I. Kraucunas, 2004: The tropical dynamical response to latent heating estimates derived from the TRMM Precipitation Radar. J. Atmos. Sci., 61, 1341-1358.

Shige, S., Y. N. Takayabu, W.-K. Tao, and D. E. Johnson, 2004: Spectral retrieval of latent heating profiles from TRMM PR data. Part I: Development of a model-based algorithm. $J$. Appl. Meteor., 43, 1095-1113.

Shimizu, S., N. Takahashi, T. Iguchi, J. Awaka, T. Kozu, R. Meneghini, and K. Okamoto, 2003: Validation analyses after the altitude change of TRMM. International Society for Optical Engineering (SPIE Proceedings, Vol. 4894), doi:10.1117/ 12.466523.

Simpson, J., R. F. Adler, and G. R. North, 1988: A proposed Tropical Rainfall Measuring Mission (TRMM) satellite. Bull. Amer. Meteor. Soc., 69, 278-295.

Stokes, G. M., and S. E. Schwartz, 1994: The Atmospheric Radiation Measurement (ARM) Program: Programmatic background and design of the cloud and radiation test bed. Bull. Amer. Meteor. Soc., 75, 1201-1221.

Sui, C.-H., and K.-M. Lau, 1989: Origin of low-frequency (intraseasonal) oscillations in the tropical atmosphere. Part II: Structure and propagation of mobile wave-CISK modes and their modification by lower boundary forcings. J. Atmos. Sci., 46, 37-56

Tao, W.-K., and Coauthors, 2006: Retrieval of latent heating from TRMM measurements. Bull. Amer. Meteor. Soc., 87, 15551572.

Thompson, R. M., Jr., S. W. Payne, E. E. Recker, and R. J. Reed, 1979: Structure and properties of synoptic-scale wave distur- 
bances in the intertropical convergence zone of the eastern Atlantic. J. Atmos. Sci., 36, 53-72.

Webb, M., C. Senior, S. Bony, and J.-J. Morcrette, 2001: Combining ERBE and ISCCP data to assess clouds in the Hadley Centre, ECMWF and LMD atmospheric climate models. Climate Dyn., 17, 905-922.

Williams, K. D., and G. Tselioudis, 2007: GCM intercomparison of cloud regimes: Present-day evaluation and climate change response. Climate Dyn., 29, 231-250, doi:10.1007/s00382-0070232-2.
Wu, Z., E. S. Sarachik, and D. S. Battisti, 2000: Vertical structure of convective heating and the three-dimensional structure of the forced circulation on an equatorial beta-plane. J. Atmos. Sci., 57, 2169-2187.

Yanai, M., S. K. Esbensen, and J.-H. Chu, 1973: Determination of bulk properties of tropical cloud clusters from large-scale heat and moisture budgets. J. Atmos. Sci., 30, 611-627.

Yuter, S. E., and R. A. Houze Jr., 1998: The natural variability of precipitating clouds over the western Pacific warm pool. Quart. J. Roy. Meteor. Soc., 124, 53-99. 